people of Mali. As Sagan points out, their astronomical knowledge is just not remarkable enough to have been learnt from little green men in UFOs and could all have been learnt from contacts with Europeans. Sagan has performed a useful service here in collecting together these examples of public gullibility and demonstrating how a mixture of deliberate fraud and uncritical thinking has allowed millions to be bamboozled throughout history.

Yet when later in the book Sagan turns to discuss religion, his own critical apparatus seems to be switched off. "These mystical insights must mean something ... If religions are fundamentally silly, why is it that so many people believe in them?" an argument which could equally be applied to belief in UFOs or astral projection. Sagan's excitement by the phenomenon of mystical visions, and his curious attempt in the last chapter of the book to link these and all religious ideas to experiences associated with birth, suggest that Sagan is about to become a "bornagain" believer in - something.

Although Sagan is rightly caustic about some of the absurdities of the popular pseudosciences he makes no effort ot discuss the problem of demarcation between science and pseudoscience, which has so occupied the attention of Karl Popper and his followers. Sagan's championing of science seems positively naive at times. Compared with the doctrines of pseudoscience ". . . science is more intricate and subtle, reveals a much richer universe and powerfully evokes our sense of wonder. And it has the additional and important virtue - to whatever extent the word has any meaning - of being true". Astrologers would obviously be happy with this statement with the word "astrology" substituted for "science". That is not what distinguishes science from pseudoscience.

On the exploration of the Solar System, Sagan is naturally interesting and thorough, for this is his own area of expertise. It would be interesting some day to hear what it is like for a scientist to work on one of these NASA missions. I find it rather touching that Sagan's belief in the existence of life elsewhere in the Universe is so passionate that he cannot bring himself to mention NASA's of ficial interpretation of the Viking Lander mission to Mars, namely that Mars is chemically but not biologically active.

In comparing Sagan with popularisers of astronomy like Hoyle or those grand old rivals Eddington and Jeans, it has to be said that he has so far set himself an easier task. Those earlier masters set out to popularise the astronomical research of their times: they were ahead of the tastes of their public and tried to take their readers with them into the world of the modern astronomer. Carl Sagan, like the efforvescent Patrick Moore, talks for the most part about the areas already popular with the public: the

Solar System, space travel, life in the Universe. Sagan's references to the "new" astronomies, radio, infrared, X-ray, and so on, seem to me to be perfunctory. He is not even particularly good on a topic which might be expected to have appealed to him, astronomy from space platforms. He refers to "an astronomical telescope in earth orbit called Copernicus", without mentioning that it is primarily the ultraviolet band that the instruments on the Copernicus satellite have opened up. $\mathrm{He}$ seems to think that $\mathrm{X}$-ray emission from gas in clusters of galaxies was discovered by the recent HEAO satellites, whereas this was one of the achievements of the pioneering Uhuru satellite launched in 1970.

Considering that most of this material has been seen or heard by the public before,

\section{In the conflux of eternities}

\section{Freeman J. Dyson}

In the Centre of Immensities. By Bernard Lovell. Pp. 174. (Hutchinson: London; Harper and Row: New York, 1979.) £5.50.

LOVELL's life-work has been the exploration of the Universe by means of radio-telescopes. He was one of the small group of pioneers who understood thirty years ago that the new science of radioastronomy would give us a wider and deeper view of the Universe than optical observations alone could provide. The achievements of the telescopes which he built have proved his vision right. In our modern theories of the structure and development of the Universe, the evidence obtained from radio observations plays a central and indispensable role.

In this book Lovell is not concerned with his own work as an observer. He is describing the historical growth of our understanding of the size and shape of the Universe and of our own situation within it. He puts this astronomical history within the context of the wider philosophical and religious struggles which have raged around the growth of modern science. He believes, in opposition to the prevailing fashion of scientific positivism, that the creative interaction between astronomy, philosophy and religion is not yet at an end. His purpose is to demonstrate that the discoveries of the past fifty years have confirmed rather than contradicted the words spoken by the mathematicianphilosopher Whitehead in 1925: "When we consider what religion is for mankind, and what science is, it is no exaggeration to say there are a couple of minor errors that ought to have been removed by now. It is not the orientation in space of a molecule that is quantised (page 17) but its angular momentum or energy. And galaxies do not disappear from view over the event horizon (page 296): on the contrary they swim into view over it. And as for the suggestion that psychedelic molecules exist in great abundance in plants because of artificial selection as a result of cultivation by human beings. . .

But these reservations do not diminish my enjoyment of the book. Broca's Brain is an entertaining collection of essays by a very good popular-science writer.

Michael Rowan-Robinson is Reader in Astronomy at Oueen Mary College, University of London, UK.

that the future course of history depends upon the decision of this generation as to the relations between them."

To readers moderately conversant with the facts of astronomy, Lovell's expository chapters describing the growth of astronomical knowledge will be easy to follow but not particularly novel. On the technical level, his exposition does no differ substantially from the accounts given in other popular books such as Steven Weinberg's The First Three Minutes (André Deutsch/Fontana: London; Basic Books: New York; for review, see Nature, 267, 291; 1977). The exciting things in Lovell's book are nontechnical. His unique quality as a thinker is displayed in the philosophical and ethical discussions with which the book begins and ends, and in the breadth of his knowledge of history and literature. Chapter 1 starts with Saint Thomas Aquinas and ends with Thomas Carlyle, both of them great writers and profound thinkers, both of them synthesisers who tried to reconcile scientific truth with religious vision, both of them destined to be pushed aside by a younger generation of impatient factfinders.

Lovell takes his title from Thomas Carlyle's "Sartor Resartus". Man, according to Carlyle, "sees and fashions for himself a Universe, with azure Starry Spaces, and long Thousands of Years. . . as it were, swathed in, and inextricably over-shrouded; yet it is sky-woven and worthy of a God. Stands he not thereby in the centre of Immensities, in the conflux of Eternities?" If Lovell's book succeeds in persuading a new generation of readers to look at the Universe through the eyes of Thomas Carlyle, it will have done us all a great service.

Freeman J. Dyson is Professor of Physics at the Institute for Advanced Study, Princeton, New Jersey. 